\title{
Assessment the Risk Factors of Patients with Septic Shock in the Intensive Care Unit
}

\author{
Nadia Adel Sayed ${ }^{1}$, Olfat Abd El-Ghany Shawer ${ }^{2}$ \& Mervat Anwar Abdel-Aziz ${ }^{3}$. \\ ${ }^{1}$. Specialist nursing, Faculty of Nursing, Assiut University, Assiut, Egypt. \\ 2. Assistant Professor of Critical \& Emergency Care Nursing, Faculty of Nursing, Assiut University, Egypt. \\ ${ }^{3 .}$ Assistant Professor of Critical \& Emergency Care Nursing, Faculty of Nursing, Assiut University, Egypt
}

\begin{abstract}
Background: Sepsis is considered to induce immune suppression, leading to increased susceptibility to secondary infections with associated late mortality. Aim: To assess the risk factors of patients with septic shock in the intensive care unit. Study design: a descriptive research design was utilized in this study. Setting: The study was conducted in the general intensive care unit and trauma intensive care unit at Assuit University Hospital. Sample: A purposive 60 patients with septic shock patients. Tools: two tools used for data collection, tool (1), Patient assessment sheet, and tool (2), risk factors assessment sheet. Results: The main risk factors were dysfunction of one or more of the major body systems, tracheostomy (65.0\%), diabetes mellitus (65.0\%) and respiratory disease, in addition, more than half of them stay more than 20 days in the ICU and half of them suffered from respiratory failure as a complication of septic shock. Conclusion: major factors that were associated with in-hospital mortality among ICU patients with severe sepsis or septic shock were multi-organ failure and DM which despite treatment with early resuscitation. Recommendation: Applied Nursing guidelines and standard precautions infection control of patients with septic shock at the onset of intensive care unit admission.
\end{abstract}

\section{Keywords: Risk Factors, Septic shock \& Intensive Care Unit.}

\section{Introduction}

Sepsis is a major health problem and an important cause of mortality in intensive care units (ICUs) worldwide. In spite of the continuous efforts to put solid criteria for early diagnosis of sepsis, it still find a challenge to accurately identify patients with sepsis in wards and/or emergency departments. It requires aggressive treatment and close monitoring in the Intensive Care Unit (ICU) (Perner et al., 2016).

Frequently, people with septic shock were cared for in intensive care units. It most commonly affects children, immune-compromised individuals, and the elderly, as their immune systems cannot deal with infection so effectively as those of healthy adults' patients suffering from severe burns and patients with physical trauma. The mortality rate from septic shock is approximately $25-50 \%$ (Kumar et al., 2013).

Diagnosis of septic shock as clinical manifestation, blood pressure, heart rate, and $\mathrm{O} 2$ monitoring complete blood count with differential, electrolyte panel and creatinine, lactate, invasive central venous pressure (CVP),partial pressure of arterial oxygen ( $\mathrm{PaO} 2)$, and central venous $\mathrm{O} 2$ saturation $(\mathrm{ScvO} 2)$ reading including wounds in surgical patients Invasive central venous pressure (CVP) (Singer, 2016).

Complications of sepsis range from less to more sever. As sepsis worsens blood flow to vital organs, such as brain heart ,and kidneys, becomes impaired
Sepsis can also cause blood clots to form in organs and arms, legs , fingers, and toes- leading to a varying degree of organs failure and tissues death (gangrene) and deep venous thrombosis (American Nurses Association, 2017).

Critically ill patients with severe sepsis or septic shock have investigated the relative significance of multiple risk factors for infection and sepsis, including; Intrinsic Factors, include; extreme of age, coexisting diseases, malignancies, burns, acquired immunodefciency syndrome (AIDS), diabetes, substance abuse, dysfunction of one or more of the major body systems, and malnutrition. While the Extrinsic Factors, include; invasive devices, medication therapy, fluid therapy, surgical and traumatic wounds, surgical and invasive diagnostic procedures, and immunosuppressive therapy (Caironi et al., 2014).

Prevention of severe sepsis and septic shock is one of the primary responsibilities of nurses in the critical care area. These measures include the identification of patients at risk and reduction of their risk factors; including exposure to invading microorganisms.Nursing interventions include early identification of sepsis syndrome; administering prescribed fluids, medications, and nutrition; providing comfort and emotional support; and preventing and maintaining surveillance for complications (Carlson \& Fitzsimmons, 2019). 
Nurse play key role in prevention of infection and implement strategies for preventing infection, the accountability which results in the promotion of patient care, the continuous surveillance of nosocomial infections, washing hands as evidence suggests that a proper hand washing reduces the rate of infections and the proper use, mechanical ventilation patients, venous catheter-related infections andsurgical-site infections (Dakshinamoorthy, 2018).

\section{Significance of the study}

Sepsis has a worldwide incidence of more than 20 million cases a year, with mortality due to septic shock reaching up to 50 percent even industrialized countries. Septic shock in the thirteenth leading cause of death in the United States and the most frequent cause of deaths in intensive care units. There has been an increase in the rate of septic shock deaths in recent decades (Ukkonen et al., 2016).

In 2016 the average number of patients with septic shock in intensive care unit at Assuit University hospital about 70 patients in general intensive care unit and about 60 in trauma intensive care unit at Assuit University hospital (Assiut University hospital intensive care unit statistical records, (2017).

From the researcher experience, it was found that the patients with septic shock increase annually so this study aimed to assess the risk factors and outcome among patients with septic shock in intensive care unit at Assuit University hospital. In addition to prevent mortality rate and reduce complications specially multiple organ dysfunction syndrome.

\section{Aim of the study}

The aim of the study is to assess the risk factors of patients with septic shock.

\section{Research Question}

What are the risk factors of septic shock among critically ill patients in the ICU?

\section{Subjects \& Methods}

Research design: A descriptive research design was utilized to fulfil the aim of this research.

Setting: The study was carried out at the general intensive care unit and trauma intensive care unit at Assuit University hospital.

\section{Sample}

A purposive sample of 60 patients male and female in the intensive care unit at Assuit university hospitals.

Inclusion criteria

1. Critical ill patient with septic shock age from 18 to 60 years old.

2. Sex: both male and female.
3. Patients with mechanical ventilations.

4. Criteria of systemic Inflammatory Response syndrome (SIRS), (body temperature $>38^{\circ} \mathrm{C}$ or $<$ $36{ }^{\circ} \mathrm{C}$, heart rate $>90$ beats $/ \mathrm{min}$, respiratory rate $>20$ breaths/min, WBCs > 12000/m3)

\section{Exclusion criteria}

Children Critical ill patient without septic shock.

\section{Technical Design:}

This study was conducted in the general intensive care unit and trauma intensive care unit at Assuit University hospital.

The data for eight months (November 2018-July 2019) on (60) critically ill patients

\section{Data collection}

Tool (I): Patients' assessment sheet

This sheet was developed by the researchers after reviewing national and international literature.

It included five parts:

Part 1: Include demographic data of patient

It included; name, age, sex, occupation, level of education and marital status in addition to medical data as date of admission, Medical diagnosis, patient past health history, and presence of any chronic disease.

\section{Part 2: Hemodynamic parameter monitoring}

It used to assess early signs and symptoms of respiratory infection. It was developed by the researcher it include hemodynamic parameters include: (temperature, pulse, respiration, Blood pressure), and central venous pressure

Part 3: Laboratory investigations and culture:

Cultures: Blood, sputum, urine (surgical or nonSurgical wound), White Blood cells (WBCs), lactate level, and ABGs.

Part 4: APACHE II score (Acute physiology and chronic health Evaluation)

Body systems were measured during the first 24 hours of ICU admission with maximum score of 71, it measure the severity of illness for patients in intensive care unit it was based on 12 physiology variable, including GCS, APACHE II score is sum of a Acute physiology and chronic health Evaluation score, It was adopted by (Godinjak et al., 2016).

Part 5: Mechanical ventilation parameters: which include mode of ventilation, tidal volume, fraction of in spired oxygen, $\left(\mathrm{FIO}_{2}\right)$, positive end expiratory pressure (PEEP) and CEPAP. PSV.

\section{Tool (II): Risk factors assessment sheet}

This tool aimed to assess the risk factors among patients with septic shock, which included: hypertension, diabetes, heart disease, respiratory disease, malignancies, and burns, dysfunction of one or more of the major body systems, COPD, asthma, smoking, trauma, tracheostomy, and chemotherapy. 


\section{Technique for data collection \\ Methods}

The study was conducted throughout the following:

Official permission to conduct the study was obtained from the general intensive care unit, trauma intensive care unit and hospital responsible authorities after explaining the aim of the study.

Development of the tools after reviewing the related national and international literature in the various aspects of the problem using books, articles, periodicals, and magazines was done.

The reliability was done to conduct the study. The Content reliability was estimated by Alpha Cronbach's test and its result was $\mathrm{R}=0.68$.

Content validity; the tools were tested for content validity by a jury of (5) experts in the field of critical care nursing and critical care medicine from Assiut university hospital and the necessary modification were done.

\section{Pilot study}

Carried out on ten percentage (10\%) (6) patient who met the predetermined selection criteria to assess the clarity and applicability of the tools.

No change was done in the assessment sheet, so the patients selected for the pilot study were included in the main study.

The tools were designed in its final format.

Field work

Once permission was granted to proceed with the proposed study researcher initiated data collection.

- Every patient diagnosed with septic shock included in the study.

- The tools were all filled with interviewing patients to explain the purpose of the study and answering the question through 30 minutes for each patient individually.

- The researcher was assessed critically ill patients suffering from septic shock using previous mentioned tools from the first day of mechanical ventilation admission and consequently daily until for three days.

- Patient data were collected by the researchers using (Tool I) to assess:

- Patient's characteristics included patient age, sex, etc... besides, medical data by assessing the medical diagnosis and family history (tool I, part 1) from the patient hospital folder.

- The researchers assess health was clinically diagnosed in patients as:

- Hemodynamic parameters as the level of temperature, pulse, Blood pressure and respiration, (tool I, part 2).

- Laboratory investigation and blood cultures WBCs count and blood culture result taken from the routine laboratory investigations which present in the patient folder, (tool I, part 3).

- Assessment of acute physiology and chronic health evaluation score using (APACHE II) scale, (tool I, part 4).

- All patients (diagnosed with septic shock) were assed connected devices to the patient's such as mechanical ventilator, invasive mechanical ventilator, non-invasive mechanical ventilator, mode, $\mathrm{FiO} 2$, PEEP, frequency, pressure support), by using (tool I, part 5) .

- Assessment risk factors among the studied patients using (Tool II) checked for its presence or absence.

\section{Ethical considerations}

- Research proposal approved from the ethics committee in the Faculty of Nursing, Assiut University.

- There is no risk for study subject during application of the research.

- The study followed common ethical- principles in clinical research.

- Informed consent was obtained from patients or guidance that is willing to participate in the study after explaining the nature and purpose of the study.

- Confidentiality and anonymity assured.

- Patients had the right to refuse to participate and or withdraw from the study without any rational any time.

- Patient privacy was considered during the collection of data.

\section{Statistical analysis}

Collected data were analyzed and tabulated. The researcher used an appropriate statistical method and tests for analysis of the result. The statistical Package for (SPSS) version (23) was used to analyze data. 


\section{Results}

Table (1): Distribution of Socio demographic data (N. =60).

\begin{tabular}{|c|c|c|}
\hline & \multicolumn{2}{|c|}{ Group $(n=60)$} \\
\hline & No & $\%$ \\
\hline \multicolumn{3}{|l|}{ Age group } \\
\hline 18 than 28 year & 27 & 45 \\
\hline From 28:38 year & 18 & 30 \\
\hline 38 to more than 50 year & 15 & 25 \\
\hline Mean \pm SD & \multicolumn{2}{|c|}{$47.5 \pm 8.3$} \\
\hline \multicolumn{3}{|l|}{ Sex } \\
\hline Male & 35 & 58.3 \\
\hline Female & 25 & 41.7 \\
\hline \multicolumn{3}{|l|}{ Occupation } \\
\hline Unemployed & 49 & 81.7 \\
\hline Employer & 11 & 18.3 \\
\hline \multicolumn{3}{|l|}{ levelof education } \\
\hline Illiterate & 36 & 60 \\
\hline Red and write & 24 & 40 \\
\hline \multicolumn{3}{|l|}{ marital status } \\
\hline Single & 12 & 20.0 \\
\hline Married & 48 & 80.0 \\
\hline
\end{tabular}

Table (2): Distribution of medical data of patient with septic shock (N. =60).

\begin{tabular}{|l|c|c|}
\hline Items & $\mathbf{N}$. & \% \\
\hline Past Medical History & & 66.7 \\
\hline Respiratory disease & 20 & 50.0 \\
\hline Renal disease & 15 & 36.7 \\
\hline Cardiovascular disease & 11 & 10.0 \\
\hline Liver disease & 3 & 43.3 \\
\hline Diabetes mellitus & 13 & 40.0 \\
\hline Hypertension & 12 & 10.0 \\
\hline Others & 3 & \\
\hline Diagnosis & & 16.7 \\
\hline Trauma (head injury, chest trauma, spinal cord injury) & 10 & 20.0 \\
\hline Strok & 12 & 10.0 \\
\hline Heart failure & 6 & 20.0 \\
\hline Respiratory failure & 12 & 16.7 \\
\hline Renal failure & 10 & 16.7 \\
\hline Intestinal obstruction & 10 & \\
\hline
\end{tabular}

Table (3): distribution of the studied patients according to hemodynamic parameter.

\begin{tabular}{|l|c|}
\hline \multicolumn{1}{|c|}{ Hemodynamic parameters } & Group $(\mathbf{N} .=60)$ \\
\cline { 2 - 2 } & Mean $\mathbf{\text { SD }}$ \\
\hline Temperature & $39.5 \pm 0.68$ \\
\hline $1^{\text {st }}$ day & $39.17 \pm 0.65$ \\
\hline $2^{\text {nd }}$ day & $38.73 \pm 0.64$ \\
\hline $3^{\text {rd }}$ day & \\
\hline Heart rate & $136.67 \pm 26.04$ \\
\hline $1^{\text {st }}$ day & $135.4 \pm 16.52$ \\
\hline $2^{\text {nd }}$ day & $126.41 \pm 18.3$ \\
\hline $3^{\text {rd }}$ day & \\
\hline Respiratory rate & $24.76 \pm 10.41$ \\
\hline $1^{\text {st }}$ day & $24.97 \pm 10.01$ \\
\hline $2^{\text {nd }}$ day & $25.86 \pm 10.07$ \\
\hline $3^{\text {rd }}$ day & \\
\hline
\end{tabular}




\begin{tabular}{|l|c|}
\hline \multicolumn{1}{|c|}{ Hemodynamic parameters } & Group (N.=60) \\
\cline { 2 - 2 } & Mean \pm SD \\
\hline Systolic blood pressure (SBB) & \\
\hline $1^{\text {st }}$ day & $85 \pm 9$ \\
\hline $2^{\text {nd }}$ day & $86.3 \pm 9.26$ \\
\hline $3^{\text {rd }}$ day & $88 \pm 12.7$ \\
\hline Diastolic blood pressure (DBB) & $52 \pm 11.26$ \\
\hline $1^{\text {st }}$ day & $55.93 \pm 7.97$ \\
\hline $2^{\text {nd }}$ day & $58 \pm 9.97$ \\
\hline $3^{\text {rd }}$ day & \\
\hline CVP & $8.3 \pm 1.12$ \\
\hline $1^{\text {st }}$ day & $8.57 \pm 1.38$ \\
\hline $2^{\text {nd }}$ day & $9.57 \pm 1.74$ \\
\hline $3^{\text {rd }}$ day & \\
\hline
\end{tabular}

Table (4): distribution of the studied patients regarding the main risk factors $(n .=60)$.

\begin{tabular}{|l|c|c|}
\hline \multirow{2}{*}{\multicolumn{1}{|c|}{ Risk Factors }} & \multicolumn{2}{c|}{ Group (N.=60) } \\
\cline { 2 - 3 } & $\mathbf{N}$. & \% \\
\hline Hypertension & 36 & 60.0 \\
\hline Diabetes & 39 & 65.0 \\
\hline Heartdisease & 13 & 21.7 \\
\hline Respiratory disease & 37 & 61.7 \\
\hline Malignancies & 4 & 6.7 \\
\hline Burns & 5 & 8.3 \\
\hline Dysfunction of one or more of the major body systems & 41 & 68.3 \\
\hline COPD.Asthma & 26 & 43.3 \\
\hline Smoking & 33 & 55.0 \\
\hline Truma & 30 & 50.0 \\
\hline Tracheostomy & 39 & 65.0 \\
\hline Chemotherapy & 6 & 10.0 \\
\hline Old age & 5 & 8.3 \\
\hline Malnutrition & 6 & 10 \\
\hline Substance abuse & - & - \\
\hline Acquired immune efficiency syndrome & 1 & 1.7 \\
\hline Invasive devices & 5 & 8.3 \\
\hline
\end{tabular}

Table (5): Means of the studied patients according to laboratory investigation:

\begin{tabular}{|l|c|}
\hline \multicolumn{1}{|c|}{ Laboratory tests } & Group (N.=60) \\
\cline { 2 - 2 } & Mean \pm SD \\
\hline Complete blood count & \\
\hline WBC & $20.74 \pm 5.79$ \\
\hline $1^{\text {st }}$ day & $17.76 \pm 6.65$ \\
\hline $2^{\text {nd }}$ day & $17.24 \pm 3.12$ \\
\hline $3^{\text {rd }}$ day & $<0.001^{* *}$ \\
\hline P.value & \\
\hline Lactate Level & $1.06 \pm 0.08$ \\
\hline $1^{\text {st }}$ day & $1.21 \pm 0.12$ \\
\hline $2^{\text {nd }}$ day & $1.25 \pm 0.13$ \\
\hline $3^{\text {rd }}$ day & $<0.001^{* *}$ \\
\hline P.value & \\
\hline
\end{tabular}


Table (6): Comparison of studied patients in $\mathbf{1}^{\text {st }}$ and $3^{\text {rd }}$ day of admission regarding laboratories cultures.

\begin{tabular}{|c|c|c|c|c|c|}
\hline \multirow{3}{*}{ Culture } & \multicolumn{5}{|c|}{ Group (N.=60) } \\
\hline & \multicolumn{2}{|c|}{$\mathbf{1}^{\text {st }}$ day } & \multicolumn{2}{|c|}{$3^{\text {rd }}$ day } & \multirow{2}{*}{ P. value } \\
\hline & No. & $\%$ & No. & $\%$ & \\
\hline Positive & 60 & 100 & 29 & 98.3 & \\
\hline Negative & 0 & 0 & 1 & 1.7 & \\
\hline \multicolumn{6}{|l|}{ Site } \\
\hline Blood & 27 & 45 & 21 & $35 / 0$ & \multirow{3}{*}{0.194} \\
\hline Sputum & 33 & 55 & 35 & 58.3 & \\
\hline Urine & 0 & 0 & 4 & 6.6 & \\
\hline \multicolumn{6}{|l|}{ Type of bacteria } \\
\hline Escherchiacoli & 29 & 48.3 & 28 & 46.7 & \multirow{3}{*}{$<0.001 * *$} \\
\hline klebsiella-preumonia & 22 & 36.7 & 23 & 38.3 & \\
\hline Pseudomonas & 9 & 15.0 & 9 & 15.0 & \\
\hline
\end{tabular}

Table (7): Means of Studied group regarding APACHE II and Glasgow Coma Scale scores.

\begin{tabular}{|l|c|}
\hline \multicolumn{1}{|c|}{} & Group (n=-60) \\
\cline { 2 - 2 } & Mean $\mathbf{S D}$ \\
\hline APACHE II & $10.77 \pm 2.83$ \\
\hline $1^{\text {st }}$ day & $11.26 \pm 3.70$ \\
\hline $2^{\text {nd }}$ day & $13.71 \pm 3.47$ \\
\hline $3^{\text {rd }}$ day & $<0.001^{* *}$ \\
\hline P.value & \\
\hline Glasgow Coma Scale & $8.11 \pm 1.15$ \\
\hline $1^{\text {st }}$ day & $7.97 \pm 1.27$ \\
\hline $2^{\text {nd }}$ day & $7.87 \pm 1.66$ \\
\hline $3^{\text {rd }}$ day & $<0.001 * *$ \\
\hline P.value & \\
\hline
\end{tabular}

Table (8): Relationship between $1^{\text {st }}$ and $3^{\text {rd }}$ days of admission regarding mechanical ventilation parameters.

\begin{tabular}{|c|c|c|c|}
\hline \multirow{2}{*}{ Modes } & \multicolumn{2}{|c|}{ Group (N.=60) } & \multirow{2}{*}{ P. value } \\
\hline & N. & $\%$ & \\
\hline \multicolumn{4}{|l|}{$\mathbf{1}^{\text {st }}$ day } \\
\hline Simv.PSV & 2 & 0.00 & \multirow{6}{*}{$<0.001 * *$} \\
\hline Simv.Pc & 10 & 0.00 & \\
\hline Simv & 5 & 3.33 & \\
\hline PSV & 13 & 43.33 & \\
\hline Cepap.PSV & 11 & 36.67 & \\
\hline Cepap & 6 & 6.67 & \\
\hline \multicolumn{4}{|l|}{$2^{\text {nd }}$ day } \\
\hline Simv.PSV & 2 & 0.00 & \multirow{7}{*}{$<0.001 * *$} \\
\hline Simv.Pc & 10 & 0.00 & \\
\hline Simv & 5 & 3.33 & \\
\hline PSV & 9 & 30.00 & \\
\hline $\mathrm{PC}$ & 2 & 6.67 & \\
\hline Cepap.PSV & 9 & 30.00 & \\
\hline Cepap & 10 & 20.00 & \\
\hline \multicolumn{4}{|l|}{$3^{\text {rd day }}$} \\
\hline Simv.PSV & 2 & 0.00 & \multirow{7}{*}{$<0.001 * *$} \\
\hline Simv.Pc & 10 & 0.00 & \\
\hline Simv & 5 & 3.33 & \\
\hline PSV & 9 & 30.00 & \\
\hline $\mathrm{PC}$ & 2 & 6.67 & \\
\hline Cepap.PSV & 8 & 26.67 & \\
\hline Cepap & 11 & 23.33 & \\
\hline
\end{tabular}


Table (9): Continue mechanical ventilation

\begin{tabular}{|c|c|}
\hline & Group $(n=60)$ \\
\hline & Mean \pm SD \\
\hline \multicolumn{2}{|l|}{ PEEP } \\
\hline $1^{\text {st }}$ day & $15.65 \pm 11.12$ \\
\hline $2^{\text {nd }}$ day & $17.52 \pm 11.38$ \\
\hline $3^{\text {rd }}$ day & $18.36 \pm 11.61$ \\
\hline P. value & $0.005 * *$ \\
\hline \multicolumn{2}{|c|}{ Tidal Volume } \\
\hline $1^{\text {st }}$ day & $625.42 \pm 59.91$ \\
\hline $2^{\text {nd }}$ day & $645.77 \pm 78.74$ \\
\hline $3^{\text {rd }}$ day & $534.08 \pm 252.15$ \\
\hline P. value & 0.239 \\
\hline \multicolumn{2}{|l|}{ Fio2 } \\
\hline $1^{\mathrm{st}}$ day & $33.23 \pm 7.73$ \\
\hline $2^{\text {nd }}$ day & $38.29 \pm 9.55$ \\
\hline $3^{\text {rd }}$ day & $38.43 \pm 9.95$ \\
\hline P. value & 0.247 \\
\hline
\end{tabular}

Table (10): Comparison Between Studied groups related to Arterial blood gases.

\begin{tabular}{|c|c|c|}
\hline & Group $(n=-60)$ & P value \\
\hline & Mean \pm SD & P. value \\
\hline \multicolumn{3}{|l|}{$\mathbf{P H}$} \\
\hline $1^{\text {st }}$ day & $7.16 \pm 1.11$ & 0.288 \\
\hline $2^{\text {nd }}$ day & $7.39 \pm 0.09$ & 0.390 \\
\hline $3^{\mathrm{rd}}$ day & $7.36 \pm 0.06$ & 0.233 \\
\hline P. value & $0.028^{*}$ & 0.205 \\
\hline \multicolumn{3}{|l|}{ Pao2 } \\
\hline $1^{\text {st }}$ day & $79.5 \pm 15.53$ & 0.755 \\
\hline $2^{\text {nd }}$ day & $82.11 \pm 10.26$ & 0.842 \\
\hline $3^{\text {rd }}$ day & $92.81 \pm 15.78$ & 0.716 \\
\hline P. value & 0.443 & 0.443 \\
\hline \multicolumn{3}{|l|}{ Paco2 } \\
\hline $1^{\text {st }}$ day & $29.93 \pm 5.83$ & $0.033 *$ \\
\hline $2^{\text {nd }}$ day & $29.07 \pm 6.01$ & 0.212 \\
\hline $3^{\text {rd }}$ day & $31.33 \pm 6.17$ & 0.894 \\
\hline P. value & $0.011^{*}$ & 0.241 \\
\hline \multicolumn{3}{|l|}{ Hco3 } \\
\hline $1^{\text {st }}$ day & $18.35 \pm 5.86$ & 0.060 \\
\hline $2^{\text {nd }}$ day & $22.05 \pm 4.16$ & 0.633 \\
\hline $3^{\text {rd }}$ day & $22.09 \pm 3.43$ & 0.259 \\
\hline P. value & $0.003 * *$ & 0.115 \\
\hline \multicolumn{3}{|l|}{ Sao2 } \\
\hline $1^{\text {st }}$ day & $78.1 \pm 10.96$ & $0.002 * *$ \\
\hline $2^{\text {nd }}$ day & $79.77 \pm 8.26$ & $<0.001 * *$ \\
\hline $3^{\text {rd }}$ day & $86.77 \pm 5.98$ & $0.001 * *$ \\
\hline P. value & $<0.001 * *$ & \\
\hline
\end{tabular}

Independent t. test p. value $<0.05 *$ statistically significant $* *$ highly significant.

Table (1): This table illustrates socio-demographic data of the studied group, that, the majority of studied patients' age was from 18 to less than 38 years old, with mean age $(47.5 \pm 8.3)$. They were male, illiterate and unemployed and married, $(58.3 \%, 60 \%, 81.7 \%$, $60 \%$, and $80 \%$ respectively).
Table (2): Represents the medical data of the studied group, that, the majority of studied patients had a history of respiratory disease and (20\%) of them diagnosed with either neurovascular disease or respiratory System disease.

Table (3): This table illustrates the mean hemodynamic parameters among studied patients, 
regarding body temperature, majority of them were elevated than normal in the $1^{\text {st }}$ and $3^{\text {rd }}$ days $(39.5 \pm 0.68$ and $38.73 \pm 0.64$ respectively) regarding heart rate in the $1^{\text {st }}$ and $3^{\text {rd }}$ days were higher than normal level with the means $(136.67 \pm 26.04$ and $126.41 \pm 18.3$ respictively). regarding systolic blood pressure during $1^{\text {st }}$ and $3^{\text {rd }}$ days, the means slightly decrease than normal during $1^{\text {st }}$ and $3^{\text {rd }}$ with means ( $85 \pm 9$ and $88 \pm 12.7$ respectively) and the diastolic blood pressure were $(52 \pm 11.26$ and $58 \pm 9.97$ respectively). The table added that; CVP means decreased during the $1^{\text {st }}$ and $3^{\text {rd }}$ day of admission were $(8.3 \pm 1.12$ and $9.57 \pm 1.74$ respectively). In addition to the respiratory rate the mean during $1^{\text {st }}$ and $3^{\text {rd }}$ days of admission increased than normal levels $(24.76 \pm 10.41$ and $25.86 \pm 10.07$ respectively).

Table (4): This table showed that the main risk factors among the studied patients with septic shock were dysfunction of one or more of the major body systems, tracheostomy, diabetes mellitus and respiratory disease $(68.3 \%, 65 \%, 65 \%$ and 61.7 respectively).

Table (5): This table illustrated that there was a statistical significant difference between $1^{\text {st }}$ and $3^{\text {rd }}$ days ether in WBC and lactate levels with mean WBC level (20.74 \pm 5.79 and17.24 \pm 3.12 respectively) and lactate level $(1.06 \pm 0.08$ and $1.25 \pm 0.13$ respictively).

Table (6): This table illustrated that all studied patient $(100 \%)$ had positive culture mainly $(55 \%)$ from sputum while (48.3\%) was Escherchiacoli among septic shock patients with significance difference between regarding the types of bacteria detected.

Table (7): This table revealed regarding APACHE II score results among patients with septic shock showed that the mean \pm SD of studied were $(10.77 \pm$ $2.83)$ in the $1^{\text {st }}$ day $(13.71 \pm 3.47)$ in the $3^{\text {rd }}$ day, with statistical significant difference $(\mathrm{p}=0.001 *)$. Regarding Glasgow Coma Scale results among septic shock patients, the mean \pm SD were $(8.11 \pm 1.15)$ in the $1^{\text {st }}$ day and $(7.87 \pm 1.66)$ in the $3^{\text {rd }}$ day, with statistical significant difference in $3^{\text {rd }}$ day ( $p$ $=0.001 *$ ).

Table (8): This table showed there was a statistical significance difference between the $1^{\text {st }}$ and $3^{\text {rd }}$ day of admission regarding mechanical ventilation parameters.

Table (9): Represents comparison between the $1^{\text {st }}$ and $3^{\text {rd }}$ days of admission as regard to the mean and stander deviation of the mechanical ventilator parameters it found that there were no statistical significant defference between in these parameters except in PEEP.

Table (10): This table showed that there was a statistically significant difference between the $1^{\text {st }}$ and $3^{\text {rd }}$ days of admission regarding sao 2 but there were no significant statistical deference regarding the remain blood gas components.

\section{Discussion}

This discussion will cover the main result findings as follow

Socio-demographic characteristics of studied patients:

The results of the current study revealed that the mean age of the studied patients was less than forty years old; this was not compatible with Vignon et al., (2018).

As regarding to sex, it was noticed that a highly percent of patients were male. This was in the same line with Stortz et al., (2018) who mentioned in his study that; majority of his studied patients were male. In spite of, this not matched with Vallabhajosyula et al., (2019) who mentioned that the cohort receiving palliative care in the ICU and high risk of septic shock was older, of white race, female sex, and with higher comorbidity and acute organ failure.

According to diagnosis and reason for ICU admission most of the patients had respiratory disorders, this was match to the result of the study of (Zeng et al., 2016) which represent in his study " Effect of probiotics on the incidence of ventilator-associated pneumonia in critically ill patients: a randomized controlled multicenter trial ", that most of their studied patients were ventilated by respiratory disease.

Regarding to physiological and hemodynamic parameters:

The results of our study revealed regarding the body temperature at the $1^{\text {st }}$ and $3^{\text {rd }}$ days, that the majority of the studied patients; temperature elevated than normal in the $1^{\text {st }}$ and $3^{\text {rd }}$ days due to bacterial infection and positive culture.

Regarding heart rate in the $1^{\text {st }}$ and $3^{\text {rd }}$ days were higher than normal level due to bacterial infection and positive culture.

Regarding systolic and diastolic blood pressure during $1^{\text {st }}$ and $3^{\text {rd }}$ days the means slightly decrease than normal during $1^{\text {st }}$ and $3^{\text {rd }}$. The data of the present study added that; CVP means decreased during the $1^{\text {st }}$ and $3^{\text {rd }}$ day of admission.

Related to respiratory rate, the mean during $1^{\text {st }}$ and $3^{\text {rd }}$ days of admission increased than normal levels. Regarding the CVP levels, the means decreased during the $1^{\text {st }}$ and $3^{\text {rd }}$ day of admission. In this respect Leone et al., (2015) revealed that; clinicians may not recognize these abnormalities in the ICU as signs of sepsis severity and may not respond appropriately with an increase in resuscitation intensity. Whether early interventions to control body temperature and restore hyperglycemia would improve outcomes, as 
opposed to these factors simply representing surrogates for under recognized illness severity, remains unclear.

Zhou et al., (2018) added that; septic shock was defined as arterial hypotension (systolic blood pressure $90 \mathrm{~mm} \mathrm{Hg}$ ) despite adequate fluid resuscitation (N1500 mL) or use of vasopressors.

Kato, \& Pinsky, (2015) concluded that; the available evidence suggests that targeting the mean arterial blood pressure of $65-70 \mathrm{mmHg}$ in a patient with septic shock who does not have chronic hypertension was a reasonable first approximation. Whereas in a patient with chronic hypertension, targeting of 80 $85 \mathrm{mmHg}$ appears to be a reasonable first step.

While Marik, (2014) found that; the vast majority of patients had available data for CVP, adding patients who died received less intravenous fluids within the first 6 hours, were more likely to be intubated, had higher initial CVP and lactate measurements, and achieved a decreased lactate clearance as compared with survivors in the septic shock patients.

Regarding the risk factors of septic shock among the studied patients

The present study showed that the main risk factors among the studied patients with septic shock were dysfunction of one or more of the major body systems, tracheostomy, diabetes mellitus and respiratory disease.

This was not in the line with Ninghui et al., (2015) who revealed that risk factors associated with multidrug-resistant Acinetobacter baumannii include older age, pneumonia, using drainage catheters, and intensive care unit stay.

Unlike Drumheller et al., (2016) focused on optimization of cardiovascular function in early severe sepsis and septic shock, little research has evaluated the significance or treatment of respiratory failure in ICU sepsis. A variety of mechanisms likely contribute to early respiratory failure and need for mechanical ventilation in sepsis

Our finding that a history of diabetes was one of the major risks of septic shock and in-hospital death among patients with severe sepsis or septic shock. Although there were consistent preclinical data linking diabetes to impaired immune functions as well as increased susceptibility to certain infections, large-scale epidemiological studies including patients with pneumonia, sepsis, or infection-related diagnoses have shown contradictory results in regard to mortality (Gotts \& Matthay, 2016).

Sundén-Cullberg et al., (2017) found an opposite finding and concluded that, clinical studies specifically examining critically ill patients with severe sepsis or septic shock have found no association between diabetes and increased mortality when controlling for other factors.
Interestingly, these and other reports have documented differing patterns of organ dysfunction among patients with diabetes, with an increased risk of renal failure but a decreased frequency of acute respiratory distress syndrome (Zador et al., 2019).

Further, the research should investigate the significance of early multi-organ dysfunction, as this remains the eventual leading cause of death among patients admitted to the ICU with severe sepsis and septic shock (Mehta et al., 2017).

McClave et al., (2016) analyzed a large data set of variables among 641 sepsis patients admitted to the ICU and found that age, serum albumin, and international normalized ratio were the factors independently associated with in-hospital mortality in multivariable regression.

Kaukonen et al., (2014) also found that a history of active malignancy was independently associated with mortality. Although this was also acutely unchangeable, it highlighted a population of severe sepsis or septic shock patients where specific interventions may be able to improve currently poor outcomes.

More systematic incorporation of cancer-specific resuscitation strategies into early clinical management and further research on targeted interventions in this susceptible and frequently encountered population were warranted (Mitchell et al., 2016).

\section{Regarding the laboratory investigations}

The present study showed that; there was a statistical significant difference between $1^{\text {st }}$ and $3^{\text {rd }}$ days ether in WBC and lactate level.

These findings did not match with Chertoff et al., (2015) who achieved a decreased lactate clearance as compared with survivors in the septic shock patients.

While Puskarich et al., (2013) concluded that; in patients in the ICU with a sepsis diagnosis, early lactate normalization during the first $6 \mathrm{~h}$ of resuscitation was the strongest independent predictor of survival and was superior to other measures of lactate kinetics.

\section{Regarding the culture results}

The existing study showed that all studied patient had positive culture mainly more than half from sputum while around half was Escherchiacoli among septic shock patients with significance difference between regarding the types of bacteria

This not match with Wani et al., (2018) who found that; Pseudomonas was the main micro-organism then Escherchiacoli among the septic shock patients.

This was not agreed with Zuli and Jun, (2015) who concluded that 520 critically ill patients. Nosocomial infection occurred in only three percentages of the studied patients.

Gelinas, \& Walley, (2016) compared with these reports, our study includes a comprehensive data set 
of a larger population of more severely ill patients that were all treated with early protocolized resuscitation. In addition, Gong et al., (2018) found critically ill patients had a well-established, protocolized, aggressive approach to early sepsis resuscitation.

Regarding Acute Physiology and Chronic Health Evaluation (APACHE) score results among septic shock patients : the results of this study shows that that the mean \pm SD of the studied group were $(10.77 \pm$ $2.83)$ in the $1^{\text {st }}$ day and $(13.71 \pm 3.47)$ in $3^{\text {rd }}$ day, With highly statistical significant difference (p $=0.001 * *$ ).

These finding disagreed with Fernández-Barat et al., (2017) who mentioned that; among the 227 patients, 25 patients received rehabilitation. Comparing the rehabilitation and control groups, there was no significant difference in gender, ages, and APACHE II score.

\section{Regarding Glasgow Coma Scale (GCS)}

The present study showed that; there was a statistical significance difference between $1^{\text {st }}$ and $3^{\text {rd }}$ days of admission in the ICU and the GCS of the studied patients was decreased. With no statistical significant difference in both groups. $(p=0.917)$.

Glasgow coma scale (GCS) was reported to be an indicator of mortality as well. Palm et al., (2016) evaluating the definition of sepsis and sepsis syndrome stated that patients with low GCS had a higher mortality rate. Researchers reported patients with a GCS of 15 had $16 \%$ mortality, those with a score of 13 to 14 had $20 \%$ mortality, those with GSC of 9 to 12 had $50 \%$ mortality, and those with GCS of 3 to 8 had $63 \%$ mortality $(\mathrm{P}<.05)$. On the contrary, Russell et al., (2016) in their retrospective study on 437 patients reported that the GCS was not significantly associated with high in hospital mortality (p. value 0.36 ).

In contrary to the previous studies, some researchers still claim that the use of GCS was not sensitive in early prediction of sepsis. For instance, Rasulo et al., (2017) believed that some cases with the unrecognized source of sepsis might present with cognitive impairment and behavioral dysfunction with normal Glasgow Coma score. Similarly, Åsa Askim et al., (2017) reported that the use of qSOFA score - with GCS $<15$ as one subcategory, was not sensitive in detecting sepsis early, and that it missed up to two thirds of sepsis patients. Thus, the introduction of a more sensitive indicator for cognitive function was still recommended for early detection of sepsis.

Glasgow Coma Score and sepsis associated mortality: Glasgow Coma score did not only predict the development of sepsis, but also had a prognostic value. Patients with low Glascow Coma Score had a high mortality rate (Freund et al., (2017).

Differences in Glasgow Coma Scales (GCS) had been associated with different mortality rates; it seemed very low GCS had mortality rates of more than twothirds of the affected patients. However, this was not reported in other studies (Seymour et al., 2016).

Finally and most importantly, association with mortality does not directly imply causation. The results identified here should serve for future interventional studies aimed at decreasing mortality from severe sepsis and septic shock in the ICU.

Regarding to Mechanical Ventilator parameters: It was observed that the present study resulted that there was a statistically significant difference between the $1^{\text {st }}$ and $2^{\text {nd }}$ days of admission in related to MV.

In addition the data of the present study represented a comparison between the $1^{\text {st }}$ and $3^{\text {rd }}$ days of admission as regard to the mean and stander deviation of the mechanical ventilator parameters it found that there were no statistical significant difference between in these parameters except in PEEP.

This was not matched with Léa et al., (2016) who concluded that there was statistical differences in the ventilator modes and the monitored respiratory variables on days 1, 2 and 3 (mean values) of IMV in all Critically ill patients with septic shock. Regarding to Cepap it was observed statistically significance differences between $1^{\text {st }}$ and $2^{\text {nd }}$ days $(P$. value $=0.0001^{*}$,

This was compatible with Sami et al., (2017) who mentioned that the patient's baseline characteristics and distribution of pathogens VAP were similar along the days. The clinical cure rate was more than half in septic shock group and three quarters in other group $(\mathrm{p}=0.59)$.

Pisani et al., (2016) discussed the best evidencedbased conventional protective targets (i.e. tidal volume $<6 \mathrm{~mL} \cdot \mathrm{kg}-1$ predicted body weight, pressure plateau $<30 \mathrm{cmH} 2 \mathrm{O}$, driving pressure $<15 \mathrm{cmH} 2 \mathrm{O}$ ) and alveolar recruitment options (e.g. higher positive end-expiratory pressure (PEEP) levels) in septic shock patients. Accordingly, the authors stress the concept that some ventilator strategies are likely to work in some subsets of patients while they could be unproductive or even detrimental in others. Less than two-thirds of patients with septic shock received protective lung ventilation; plateau pressure was measured in only forty percentage of the cases whereas $<20 \%$ of patients customary PEEP levels $>12 \mathrm{cmH} 2 \mathrm{O}$

Chiumello et al., (2017) founded that very disappointingly, clinical outcomes of septic shock are independently associated with economic resources; in fact, hospital survival was significantly lower in 
middle-income countries than in high-income countries.

Similarly, On the contrary, the Gajic study found higher airway pressures (peak inspiratory, plateau, and driving pressures), lower PEEP, and higher respiratory rate accompanying with higher hospital mortality, along with older age and $\operatorname{ARF}$ ( Gajic et al., 2011)

Carteaux et al., (2016) revealed the factors related hyperventilatory pattern in severely hypoxemic patients as was suggested by the correlation found between tidal volume values $>9.5 \mathrm{~mL} \cdot \mathrm{kg}-1$ predicted body weight and mortality rate in noninvasively ventilated ARF.

Narendra et al., (2017) founded that; less than twothirds of patients with septic shock received protective lung ventilation; plateau pressure was measured in solitary $40.1 \%$ of the cases whereas one fifth of patients received PEEP levels $>12 \mathrm{cmH} 2 \mathrm{O}$.

\section{Regarding arterial blood gas parameters}

The present study noticed no statistical significant difference between $1^{\text {st }}$ and $3^{\text {rd }}$ days of admission related to $\mathrm{PH}, \mathrm{PaCo}_{2}, \mathrm{HCO}_{3}, \mathrm{SaO}_{2}$. At 3rd day, it was noticed statistical significant difference related to, $\mathrm{SaO}_{2}(\mathrm{p}=<0.05)$.

Das et al., (2018) mentioned that, the individual ABG parameters had a significant positive correlation with septic shock treatment outcome: $\mathrm{pH}$ $(\mathrm{p}=0.034), \quad \mathrm{HCO} 3-(\mathrm{p}=0.034), \quad \mathrm{PaO} 2(\mathrm{p}=0.035)$, $\mathrm{PaCO} 2(\mathrm{p}=0.045)$, added that acid-base status is frequently assessed in severe sepsis and septic shock.

Sepsis, in association with multisystem organ failure and shock, may lead to respiratory failure, acute kidney injury, organ dysfunction, metabolic acidosis, and shock; thus, evaluation and management of acidbase status is frequently required (Greco et al., 2017). The study by Weiss et al., (2015) mentioned that the patients suffer from ARF had hypercapnia episode similar efficiency as for subjects with septic shock. In addition, Smart et al., (2018) founded in their study that; A proportion of patients with more severe disease will have a respiratory acidosis $(\mathrm{pH}<7.35$ and $\mathrm{PaCO} 2>6 \mathrm{k} \mathrm{Pa})$ as a result of acute on chronic respiratory failure. Acidosis is associated with augmented mortality also a developed need for intubation

Toubiana et al., (2016) recommended that all patients with septic shock with a respiratory acidosis $(\mathrm{pH}<7.35)$ should receive NIV,9 and the British Thoracic Society published guidelines which recommended that NIV should be given to those with a $\mathrm{pH}$ of $<7.25$ and should be painstaking for those with a $\mathrm{pH}$ between 7.25 and 7.35 .

In spit Lymperopoulou et al., (2015) founded that $(\mathrm{PaO} 2)$ in the $47 \%$ of patients who were hypercapnia, with a $\mathrm{PaO} 2$ of $>10 \mathrm{kPa}$ being associated with acidosis in most hypercapnia patients. $80 \%$ persisted acidotic after initial treatment.

\section{Conclusion}

Based on the result of the present study, it was concluded that

- Regarding hemodynamic parameters, (body temperature respiration and pulse) majority of the studied patients had elevated levels than normal in the $1^{\text {st }}$ and $3^{\text {rd }}$ days but regarding blood pressure and CVP, they had slightly decrease than normal.

- The main risk factors among the studied patients with septic shock were dysfunction of one or more of the major body systems (68.3\%), tracheostomy $(39 \%)$, diabetes mellitus (39\%) and respiratory disease $(37 \%)$.

- All studied patient (had a positive culture mainly from sputum with Escherchiacoli among septic shock patients with significance difference between regarding the types of bacteria detected.

- There was a statistical significance difference between the $1^{\text {st }}$ and $3^{\text {rd }}$ day of admission regarding mechanical ventilation parameters but there was no statistically significant regarding the means and SD of these parameters except in PEEP.

\section{Recommendations}

Based on the findings of the present study, the following recommendations were derived:

- Continued nursing guidelines at critical care units should be organized.

- Adequate supplies and facilities should be available in the unit.

- Replication of the study on a larger probability sample acquired from the different geographical area in ICU to figure out the main aspects of this problem.

- Apply infection control nursing guidelines and standard precautions in the intensive car unite for critically ill patients.

\section{References}

1. Americans Nurses Association, (2017): Surviving Sepsis Campaign gidelines vol $1 \mathrm{pp}$ 800- 274

2. Askim Å., Moser, F, Gustad L., Stene H., Gundersen M., Åsvold B., (2017): Poor performance of quickSOFA (qSOFA) score in predicting severe sepsis and mortality - a prospective study of patients admitted with infection to the emergency department. Scand J Trauma

Resusc Emerg Med. BioMed Central,25(1):56. 
3. Assiut University hospital intensive care unit statistical records, (2017).

4. Caironi, P., Tognoni, G., Masson, S., Fumagalli, R., Pesenti, A., Romero, M., \& Iapichino, G., (2014): Albumin replacement in patients with severe sepsis or septic shock. New England Journal of Medicine, 370(15), 14121421.

5. Carlson, B., \& Fitzsimmons, L., (2019): Shock, sepsis, and multiple organ dysfunction syndrome. Priorities in Critical Care Nursing-EBook, 474.

6. Carteaux G., Millán- Guilarte T., \& De Prost N., (2016): Failure of noninvasive ventilation for de novo acute hypoxemic respiratory failure. Crit Care Med, 44: 282-290.

7. Chertoff, J., Chisum, M., Garcia, B., \& Lascano, J., (2015): Lactate kinetics in sepsis and septic shock: a review of the literature and rationale for further research. Journal of intensive care, 3(1), 39

8. Chiumello D., Brochard L., \& Marini J., (2017): Respiratory support in patients with acute respiratory distress syndrome: an expert opinion. Critical Care; P.P.21: 240

9. Dakshinamoorthy, S., (2018): Compliance of Infection Control VAP Bundle in Critical Care Unit Nurses in Tertiary Care Hospital at Chennai. International Journal of Nursing Education, 10(1).

10. Das, S., Ghosh, K., Hazra, A., Sen, C., \& Goswami, A., (2018): Is elevated blood glucose a marker of occult tissue hypoperfusion in offpump coronary artery bypass grafting?. Annals of cardiac anaesthesia, 21(4), 393.

11. Drumheller, B., Agarwal, A., Mikkelsen, M., Sante, S., Weber, A., Goyal, M., \& Gaieski, D., (2016): Risk factors for mortality despite early protocolized resuscitation for severe sepsis and septic shock in the emergency department. Journal of critical care, 31(1), 13-20

12. Fernández-Barat, L., Ferrer, M., De Rosa, F., Gabarrús, A., Esperatti, M., Terraneo, S., \& Torres, A., (2017): Intensive care unit-acquired pneumonia due to Pseudomonas aeruginosa with and without multidrug resistance. Journal of Infection, 74(2), 142-152

13. Freund Y., Lemachatti N., Krastinova E., Van Laer M., Claessens Y., \& Avondo A., (2017): Prognostic Accuracy of Sepsis-3 Criteria for In-Hospital Mortality Among Patients With Suspected Infection Presenting to the Emergency Department. Jama.,317(3):301.

14. Gajic O., Dabbagh O., Park P., Adesanya A., Chang SY., Hou P., Anderson H., Hoth J., Mikkelsen M., \& Gentile N., (2011): U.S.
Critical Illness and Injury Trials Group: Lung Injury Prevention Study Investigators (USCIITG-LIPS). Early identification ofpatients at risk of acute lung injury: evaluation of lung injury prediction score in a multicenter cohort study. Am J Respir Crit Care Med;183: 462470.

15. Gelinas, J., \& Walley, K., (2016): Beyond the Golden Hours: Caring for Septic Patients After the Initial Resuscitation. Clinics in chest medicine, 37(2), 347-365.

16. Godinjak, A., Iglica, A., Rama, A., Tančica, I., Jusufović, S., Ajanović, A., \& Kukuljac, A., (2016): Predictive value of SAPS II and APACHE II scoring systems for patient outcome in a medical intensive care unit. Acta medica academica, 45(2).

17. Gong, Y., Liu, J., \& Ma, P., (2018): Early fluid loading for septic patients: Any safety limit needed?. Chinese Journal of Traumatology, 21(1), 1-3.

18. Gotts, J., \& Matthay, M., (2016): Sepsis: pathophysiology and clinical management. Bmj, 353, i1585.

19. Greco, E., Lupia, E., Bosco, O., Vizio, B., \& Montrucchio, G., (2017): Platelets and multiorgan failure in sepsis. International journal of molecular sciences, 18(10), 2200.

20. Kato, R., \& Pinsky, M., (2015): Personalizing blood pressure management in septic shock. Annals of intensive care, 5(1), 1-10.

21. Kaukonen, K., Bailey, M., Suzuki, S., Pilcher, D., \& Bellomo, R., (2014): Mortality Related to Severe Sepsis and Septic Shock Among Critically III Patients in Australia and New Zealand, 2000-2012. JAMA. 311, 1308-1316.

22. Kumar, V., Abbas, A., \& Fausto, N., (2013): Robbins Basic Pathology (8th ed.). Saunders, Elsevier. pp. 102-3.

23. Léa Fialkow, Maurício FarenzenaI, Iuri Christmann Wawrzeniak, Janete Salles Brauner, Sílvia Regina Rios Vieira, Alvaro Vigo, \& Mary Clarisse Bozzetti, (2016): Mechanical ventilation in patients in the intensive care unit of a general university hospital in southern Brazil: an epidemiological study, Clinics vol.71 no.3 São Paulo Mar.

24. Leone, M., Asfar, P., Radermacher, P., Vincent, J., \& Martin, C., (2015): Optimizing mean arterial pressure in septic shock: a critical reappraisal of the literature. Critical Care, 19(1), 101

25. Lymperopoulou, K., Velissaris, D., Kotsaki, A., Antypa, E., Georgiadou, S., Tsaganos, T., \& Orfanos, S., (2015): Angiopoietin-2 
associations with the underlying infection and sepsis severity. Cytokine, 73(1), 163-168.

26. Marik, P., (2014): Early management of severe sepsis: concepts and controversies. Chest, 145(6), 1407-1418

27. McClave, S., Taylor, B., Martindale, R., Warren, M., Johnson, D., Braunschweig, C., \& Gervasio, J., (2016): Guidelines for the provision and assessment of nutrition support therapy in the adult critically ill patient: Society of Critical Care Medicine (SCCM) and American Society for Parenteral and Enteral Nutrition (ASPEN). Journal of Parenteral and Enteral Nutrition, 40(2), 159-211.

28. Mehta, N., Skillman, H., Irving, S., Coss-Bu, J., Vermilyea, S., Farrington, E., \& Braunschweig, C., (2017): Guidelines for the provision and assessment of nutrition support therapy in the pediatric critically ill patient: Society of Critical Care Medicine and American Society for Parenteral and Enteral Nutrition. Journal of Parenteral and Enteral Nutrition, 41(5), 706-742.

29. Mitchell, B., Ferguson, J., Anderson, M., Sear, J., \& Barnett, A., (2016): Length of stay and mortality associated with healthcareassociated urinary tract infections: a multi-state model. J Hosp Infect. 93, 92-99

30. Narendra D., Hess D., \& Sessler C., (2017): Update in management of severe hypoxemic respiratory failure. Chest; 152: 867-879

31. Ninghui Guo M., Wencheng Xue. , Dahai T., Jinya D., \& Bin Z., (2015): Risk factors and outcomes of hospitalized patients with blood infections caused by multidrug-resistant Acinetobacter baumannii complex in a hospital of Northern China, American Journal of Infection Control, Volume 44, Issue 4, 37-39

32. Palm, R., Jünger, S., Reuther, S., Schwab, C., Dichter, M., Holle, B., \& Halek, M., (2016): People with dementia in nursing home research: a methodological review of the definition and identification of the study population. BMC geriatrics, 16(1), 78 .

33. Perner, A., Gordon, A., De Backer, D., Dimopoulos, G., Russell, J., Lipman, J., \& Walsh, T., (2016): Sepsis: frontiers in diagnosis, resuscitation and antibiotic therapy. Intensive care medicine, 42(12), 19581969.

34. Pisani L., Corcione N., \& Nava S., (2016): Management of acute hypercapnic respiratory failure. Curr Opin Crit Care; 22: 45-52

35. Puskarich, M., Trzeciak, S., Shapiro, N., Albers, A., Heffner, A., Kline, J., \& Jones, A., (2013): Whole blood lactate kinetics in patients undergoing quantitative resuscitation for severe sepsis and septic shock. Chest, 143(6), 15481553

36. Rasulo F., Bellelli G., Ely E., Morandi A., Pandharipande P., \& Latronico N., (2017): Are you Ernest Shackleton, the polar explorer? Refining the criteria for delirium and brain dysfunction in sepsis. Journal of Intensive Care,5(1):23. 16.

37. Russell D., Carmen P., Alexander I., Arthur Y., Ingrid B., Gregory S., \& Martin J., (2016): Utility of Pre-Hospital Glasgow Coma Scale in Predicting In-Hospital Mortality in Patients with Sepsis [Internet]. AM J Respir Crit Care Med Available from:http://www.atsjournals.org/doi/abs/10.116 4/ajrccmconference.2016.193.1_MeetingAbstrac ts.A7619

38. Sami Abdellatif, Ahlem Trifi., Foued Daly, Khaoula Mahjoub, Rochdi Nasri \& Salah Ben Lakha, 1., (2017): Efficacy and toxicity of aerosolised colistin in ventilator-associated pneumonia: a prospective, randomised trial, Annals of Intensive Care volume 6, Article number: 26.

39. Seymour C., Liu V., Iwashyna T., Brunkhorst F., Rea T., Scherag A., (2016): Assessment of Clinical Criteria for Sepsis. Jama.,315(8):762.

40. Singer M., Deutschman C., Seymour C., Shankar-Hari M., Annane D., Bauer M., Bellomo R., Bernard G., Chiche J., Coopersmith C., Hotchkiss R., Levy M., Marshall J., Martin G., Opal S., Rubenfeld G., van der Poll T., Vincent J., \& Angus D., (2016): "The Third International Consensus Definitions for Sepsis and Septic Shock (Sepsis3)". 315 (8): 801-810

41. Smart, L., Bosio, E., Macdonald, S., Dull, R., Fatovich, D., Neil, C., \& Arendts, G., (2018): Glycocalyx biomarker syndecan-1 is a stronger predictor of respiratory failure in patients with sepsis due to pneumonia, compared to endocan. Journal of critical care, 47, 93-98.

42. Stortz, J., Mira, J., Raymond, S., Loftus, T., Ozrazgat-Baslanti, T., Wang, Z., \& Brumback, B., (2018): Benchmarking clinical outcomes and the immunocatabolic phenotype of chronic critical illness after sepsis in surgical intensive care unit patients. The journal of trauma and acute care surgery, 84(2), 342-349.

43. Sundén-Cullberg, J., Rylance, R., Svefors, J., Norrby-Teglund, A., Björk, J., \& Inghammar, M., (2017): Fever in the emergency department predicts survival of patients with severe sepsis and septic shock 
admitted to the ICU. Critical care medicine, 45(4), 591-599

44. Toubiana, J., Courtine, E., Tores, F., Asfar, P., Daubin, C., Rousseau, C., \& Mira, J., (2016): Association of REL polymorphisms and outcome of patients with septic shock. Annals of intensive care, 6(1), 28.

45. Ukkonen, M., Karlsson, S., Laukkarinen, J., Rantanen, T., Paajanen, H., \& Finnsepsis Study Group. (2016): Severe Sepsis in Elderly Patients Undergoing Gastrointestinal Surgerya Prospective Multicenter Follow-up Study of Finnish Intensive Care Units. Journal of Gastrointestinal Surgery, 20(5), 1028-1033.

46. Vallabhajosyula, S., Prasad, A., Dunlay, S., Murphree Jr, D., Ingram, C., Mueller, P., \& Barsness, G., (2019): Utilization of Palliative Care for Cardiogenic Shock Complicating Acute Myocardial Infarction: A 15-Year National Perspective on Trends, Disparities, Predictors, and Outcomes. Journal of the American Heart Association, 8(15), e011954

47. Vignon, P., Begot, E., Mari, A., Silva, S., Chimot, L., Delour, P., \& François, B., (2018): Hemodynamic assessment of patients with septic shock using transpulmonary thermodilution and critical care echocardiography: a comparative study. Chest, 153(1), 55-64.

48. Wani, M., Chalkoo, M., Rather, Z., Yousuf, A., Arsalan, S., Lone, Z., \& Bhat, A., (2018): Clinico-pathological Profile of Pyogenic Liver Abscess: An Experience from Tertiary Care Hospital from Kashmir Valley. Journal of Advances in Medicine and Medical Research, 113

49. Weiss, S., Selak, M., Tuluc, F., Villarroel, J., Nadkarni, V. M., Deutschman, C. S., \& Becker, L., (2015): Mitochondrial dysfunction in peripheral blood mononuclear cells in pediatric septic shock. Pediatric critical care medicine: a journal of the Society of Critical Care Medicine and the World Federation of Pediatric Intensive and Critical Care Societies, 16(1), e4.

50. Zador, Z., Landry, A., Cusimano, M., \& Geifman, N., (2019): Multimorbidity states associated with higher mortality rates in organ dysfunction and sepsis: a data-driven analysis in critical care. Critical Care, 23(1), 247

51. Zeng, J., Wang, C., Zhang, F., Qi, F., Wang, S., Ma, S., \& Qu, Y., (2016): Effect of probiotics on the incidence of ventilatorassociated pneumonia in critically ill patients: a randomized controlled multicenter trial. Intensive care medicine, 42(6), 1018-1028
52. Zhou, X., Ding, B., Ye, Y., Tang, G., \& Zhang, Z., (2018): An appropriate mean arterial pressure (MAP) does not always mean hemodynamic stability in septic shock patients. Journal of critical care, 43, 397-398.

53. Zuli Z., \& Jun D., (2015): Nosocomial pneumonia in non-invasive ventilation patients: incidence, characteristics, and outcomes, Journal of Hospital Infection, Volume 91, Issue 2, 153157. 